\title{
Vestibular hyperreactivity in patients with idiopathic spasmodic torticollis
}

\author{
P L M HUYGEN, ${ }^{*} \ddagger$ W I M VERHAGEN, $\uparrow$ J J M VAN HOOF, $†$ M W I M HORSTINK $\ddagger$ \\ From the Departments of Otolaryngology* and Neurology, $\uparrow$ Academic Hospital $\ddagger$ and Canisius-Wilhelmina \\ Hospital, Nijmegen, The Netherlands
}

SUMMARY Ocular motor tests performed on 14 patients with idiopathic spasmodic torticollis were normal. The vestibulo-ocular reflex tested in eight patients showed a significant high level in seven. It is suggested that this phenomenon is secondary rather than the cause of spasmodic torticollis.

Idiopathic spasmodic torticollis (ST) is clinically defined as an abnormal involuntary contraction of the muscles of the neck resulting in more or less sustained movements and/or abnormal head posture.' Although the aetiology is unknown, the disorder is usually considered to involve the extrapyramidal system, especially the basal ganglia. From animal studies it is well known that vestibular lesions may cause similar alterations (torsion) in head posture. ${ }^{2}$ Hyndman, ${ }^{3}$ after several other authors (for the older literature, see refs $3,6,7)$, suggested that the vestibular system may be involved in patients with ST. Vestibular lesions have been made in an attempt to treat ST, ${ }^{34}$ and there have been several studies on vestibular function. ${ }^{3-7}$ In our opinion, as far as canal reflexes are concerned, these are unsatisfactory, because the authors either did not reach firm conclusions ${ }^{57}$ and, if they did, those conclusions are not based on statistical tests with properly established normal limits of reliable response parameters (see Discussion). ${ }^{6}$ Nevertheless, some tendency for directional preponderance (DP) of nystagmus towards the side opposite to the head deviation seems to be the common denominator in those reports. ${ }^{5-7}$ In this study, the issue of whether or not there is a significant DP of rotatory induced nystagmus ${ }^{6}$ was taken up again and an attempt was made to assess the absolute level of the vestibuloocular reflex (VOR) in ST, this being an issue that has

Address for reprint requests: Dr P L M Huygen, Department of Otolaryngology, Academic Hospital Nijmegen, Philips van Leydenlaan 15, $6500 \mathrm{HB}$ Nijmegen, The Netherlands.

Received 22 March 1988 and in final revised form 17 December 1988. Accepted 19 December 1988 attracted little attention in previous research. Fourteen patients with ST were examined; other clinical data have been presented elsewhere. ${ }^{8}$

\section{Material and methods}

The ST patients included four men and 10 women (two were sisters), age 32-63 years, without otological, visual or other neurological symptoms.

The patients were examined in total darkness with their eyes open to see whether spontaneous nystagmus (that is, slow phase velocity higher than $6^{\circ} / \mathrm{s}$ ) occurred. Gaze was tested in eccentric horizontal and vertical positions. Smooth pursuit was tested with a light dot moving at $20 \% \mathrm{~s}$ and optokinetic nystagmus was elicited with projected shadow stripes, $7 \cdot 5^{\circ}$ wide and at $7.5^{\circ}$ separation, moving at $40-80^{\circ} / \mathrm{s}$ over a hemicylindrical screen covering a visual angle $120^{\circ}$ wide and $80^{\circ}$ high. Velocity steps (VS) of $90^{\circ} / \mathrm{s}$ were performed after constant rotation in clockwise and counterclockwise direction. The patient was seated on a rotatory chair (Tönnies) in total darkness with eyes open and the head $30^{\circ}$ in anteflexion to place the horizontal semicircular canals in the earth-horizontal plane of rotation. In one patient, who showed about $40^{\circ}$ persistent lateral tilt of the head, the response level was corrected for the stimulus attenuation factor, that is $\cos \left(40^{\circ}\right)$. Nystagmus was measured with DCcoupled electronystagmography and analysed as previously reported. ${ }^{910}$ Calibration of horizontal eye movement was performed before each rotation. The response parameters relevant to vestibular diagnosis are: extrapolated initial velocity $\mathrm{V}\left({ }^{\circ} / \mathrm{s}\right)$ of the slow phase velocity (SPV) of postrotatory nystagmus, time constant $T(s)$, that is, the time needed to let SPV decay from V to $0.37 \mathrm{~V}$ and "Gesamtamplitude" $\mathrm{G}$, which is the product $\mathrm{V} \times \mathrm{T}$ (in degrees)." Asymmetry is measured with the directional preponderance (DP) value: $\mathrm{DP}(\mathrm{X})=100 \%(\mathrm{Xr}-\mathrm{XI}) /(\mathrm{Xr}+\mathrm{Xl})$, in which $\mathrm{X}$ denotes a general variable $(\mathrm{V}, \mathrm{T}$ or $\mathrm{G})$ and $\mathrm{r}$ and 1 right- and 
left-beating nystagmus. Normal values for the above parameters, based on upper $5 \%$ percentiles, have already been reported. ${ }^{12} \mathrm{~A}$ diagnosis of vestibular hyperreactivity was made if any of the response parameter values exceeded the normal limits. Caloric tests (water at $30^{\circ}$ and/or $44^{\circ} \mathrm{C}$, approximately $150 \mathrm{ml}$ irrigated in exactly 20 seconds) were performed for the assessment of labyrinthine lesions. The average SPV at the culmination of the postcaloric response (eyes open in the dark) was calculated in the computer analysis ${ }^{9}$ to see whether both sides reacted normally and with sufficient symmetry.

In two patients only the ocular motor tests could be performed; other tests were not possible because of their extreme torticollis. In another two patients VS tests were avoided, because they had involuntary head movements which would have caused a complex pattern of rotatory stimulation; these patients were being treated with benzodiazepine. In another patient the VS test had to be discontinued because it made him sick and one patient was excluded from the VOR evaluation because he was taking haloperidol. None of the other patients was taking drugs suspected to influence the VOR. Thus, ocular motor tests were available in 14 patients, caloric tests in 11 and VS tests in eight of these latter cases.

\section{Results}

Spontaneous nystagmus with SPV higher than $6 \%$ was absent in all 14 patients. Five patients had spontaneous nystagmus of lower SPV; the one taking haloperidol showed nystagmus to the right $\left(5^{\circ} / \mathrm{s}\right)$, the others nystagmus to the left with SPV $3-4^{\circ} / \mathrm{s}$ (no 8 in the table) or $1-2^{\circ} / \mathrm{s}$ (no 1 and no 4 in table). Ocular motor responses, including gaze positions, smooth pursuit and optokinetic responses, were normal in all 14 patients. As presented in the table, all eight patients tested (except the youngest, who had the mildest form of ST), showed abnormal VS responses typical of vestibular hyperreactivity with high gain. ${ }^{111}$

Of the patients who underwent the VS test, four had a head deviation (chin twist) to the right and four to the left (table). There was no significant difference
(Student's $t$ test) between the mean values of any of the measured response parameters ipsi- and contralateral to the head deviation. Significant high DP values were found in only two patients with DP(T and/or G) in the direction opposite that of head deviation.

Only in case 6 did the caloric responses reveal evidence of mild, unilateral, labyrinthine weakness (the side effect, calculated with a formula similar to that used for the DP, was $28 \%$ ). In this patient the DP was towards the weakest labyrinth. Borderline abnormal side effects were found in case $4(18 \%)$ and in another patient $(22 \%)$ who did not undergo VS tests. In all three cases the weakest labyrinth was on the side opposite the head deviation.

\section{Discussion}

No substantial spontaneous nystagmus was found in the primary or recumbent position in the present study, in contrast with other reports, ${ }^{5-7}$ where criteria are not specified. Substantial DP of optokinetic nystagmus, that is, in excess of $30 \%$ based on the SPV as defined in our laboratory, was not found. This is in contrast to the report by Bronstein and Rudge ${ }^{6}$ though they do not specify the criterion for relevant optokinetic DP. Remarkably, these authors reported smooth pursuit responses to be normal in most cases, ${ }^{6}$ whereas we are accustomed to a close correlation between abnormalities, if present, of smooth pursuit and optokinetic responses. ${ }^{10}{ }^{13}$ Again, we do not know Bronstein and Rudge's criterion for abnormal DP of VS responses. Their measure of DP was based on the duration of postrotatory nystagmus. That parameter has been influenced by the reported coexistent spontaneous nystagmus in a substantial number of their patients, particularly at the relatively low VS amplitude of $40^{\circ} / \mathrm{s}$. The DP of sinusoidal nystagmus responses reported in five patients is not substantiated by quantitative analysis. ${ }^{6}$

It is interesting to see that other reports indicate

Table Relevant findings in VS responses in 8 patients with $S T$

\begin{tabular}{|c|c|c|c|c|c|c|c|c|c|}
\hline \multirow[b]{2}{*}{$\begin{array}{l}\text { Patient nr } \\
\text { Sex } \\
\text { Age (yrs) } \\
\operatorname{Vr}(\mathrm{deg} / \mathrm{s}) \\
\end{array}$} & \multicolumn{4}{|c|}{$S T$ to the right } & \multicolumn{4}{|c|}{$S T$ to the left } & \multirow[t]{2}{*}{ Confidence limit $^{\prime 2}$} \\
\hline & $\begin{array}{l}1 \\
\mathrm{f} \\
50 \\
60 \\
\end{array}$ & $\begin{array}{l}2 \\
\mathrm{~m} \\
32 \\
45 \\
\end{array}$ & $\begin{array}{l}3 \\
f \\
45 \\
80 \\
\end{array}$ & $\begin{array}{l}4 \\
f \\
51 \\
70 \\
\end{array}$ & $\begin{array}{l}5 \\
\mathrm{f} \\
47 \\
90 \\
\end{array}$ & $\begin{array}{l}6 \\
f \\
63 \\
70 \\
\end{array}$ & $\begin{array}{l}7 \\
\mathrm{f} \\
51 \\
45 \\
\end{array}$ & $\begin{array}{l}8 \\
\mathrm{~m} \\
52 \\
100 \\
\end{array}$ & \\
\hline $\begin{array}{l}\text { Vl (deg/s) } \\
\text { DP(V) (\%) } \\
\operatorname{Tr}(\mathrm{s})\end{array}$ & $\begin{array}{l}\overline{75} \\
-11 \\
17\end{array}$ & $\begin{array}{l}\overline{50} \\
-5 \\
15\end{array}$ & $\begin{array}{l}\overline{70} \\
7 \\
17\end{array}$ & $\begin{array}{l}\overline{80} \\
-7 \\
15\end{array}$ & $\begin{array}{l}\overline{80} \\
9 \\
17\end{array}$ & $\begin{array}{l}\overline{70} \\
0 \\
31\end{array}$ & $\begin{array}{l}\overline{55} \\
-10 \\
24\end{array}$ & $\begin{array}{l}\overline{120} \\
-9 \\
21\end{array}$ & $+1-25$ \\
\hline $\begin{array}{l}\text { Tl (s) } \\
\text { DP(T) (\%) } \\
\text { Gr (deg) }\end{array}$ & $\begin{array}{l}\overline{25} \\
-19 \\
1020 \\
\end{array}$ & $\begin{array}{l}\overline{16} \\
-3 \\
675 \\
\end{array}$ & $\begin{array}{l}\overline{17} \\
0 \\
1360 \\
\end{array}$ & $\begin{array}{l}21 \\
-17 \\
1050\end{array}$ & $\begin{array}{l}\frac{1}{26} \\
-21 \\
1530 \\
\end{array}$ & $\begin{array}{l}13 \\
41 \\
2170\end{array}$ & $\begin{array}{l}\frac{7}{27} \\
-6 \\
1080\end{array}$ & $\begin{array}{l}\frac{1}{20} \\
2 \\
2100\end{array}$ & $\begin{array}{l}26 \\
+/-25\end{array}$ \\
\hline $\begin{array}{l}\text { Gl (deg) } \\
\mathrm{DP}(\mathbf{G})(\%)\end{array}$ & $\begin{array}{l}1875 \\
-30\end{array}$ & $\begin{array}{l}800 \\
-8\end{array}$ & $\frac{7190}{7}$ & $\begin{array}{l}1680 \\
-23\end{array}$ & $\begin{array}{l}2080 \\
-15\end{array}$ & 41 & $\begin{array}{l}1485 \\
-16\end{array}$ & $\begin{array}{l}2040 \\
-7\end{array}$ & $\begin{array}{l}1135 \\
+/-25\end{array}$ \\
\hline
\end{tabular}


substantial $\mathrm{DP}^{6}$ or at least a tendency for $\mathrm{DP},{ }^{57}$ of caloric responses in the direction opposite the head deviation. It is difficult to compare the caloric DP values given by other authors with the present caloric DP values because they are based on nystagmus frequency ${ }^{5}$ or duration, ${ }^{6}$ and have a different mathematical definition ${ }^{6}$ or unclear confidence limits, or both. ${ }^{67}$ The DP values presumably based on SPV at culmination like ours - (we did not measure duration)-are reported to yield substantial preponderance in three out of seven patients, ${ }^{7}$ which is similar to the present two out of eight score for rotatory DP. In the present study we preferred the evaluation of rotatory DP values because these can be directly derived, whereas DP values based on caloric responses are indirect. The stimuli are more likely to be applied in strictly symmetrical fashion in rotatory rather than caloric tests as they do not rely on parameters which depend on the anatomical condition of the middle ear. In our experience, DP measures of rotatory and caloric responses tend to be most consistent if caused by a canal paresis, with or without the tendency for a spontaneous nystagmus beating to the intact side. Interestingly, canal paresis was not a relevant finding in this or any of the other studies on ST..$^{5-7}$

VOR responses with significant high gain, indicating vestibular hyperreactivity, appeared to be typical of the present group of ST patients. This is a new finding in this disorder. A simple explanation would be that this was caused by false positivity. Although the probability of false positivity is rather high and can be estimated to be in the range $14-26 \%,{ }^{12}$ the binomial table for sample size 8 indicates that five observations is the upper $95 \%$ confidence limit for the above percentages of false positivity, whereas seven observations were made. The very high parameter values found in many of the present patients (table) also indicate that pseudosignificance caused by normal variability around the borderline between normal and abnormal is unlikely. So the finding of vestibular hyperreactivity is significant and, although it is known to occur in other conditions such as multiple sclerosis, cerebellar disorders and hyperventilation, ${ }^{10-12}$ it is tempting to look for an explanation which is specific to ST. In subjects who are free to move their head, body movements elicit vestibulo-ocular, vestibulocollicular, cervico-ocular and optokinetic reflexes in subtle interplay with the ultimate goal of optimal gaze stabilisation. ${ }^{14}$ If the head is fixed on the body the gain of the VOR, that is, measured as eye-in-head movements, may account for almost all the eye movement required to compensate for rotatory head movement. ${ }^{15}$ Thus it is possible that in freely moving subjects with a fixed neck, such as torticollis, a plastic enhancement of the VOR gain measured for eye-inhead movement would compensate for the loss of compensatory head movement.

It is possible that a vestibular abnormality is secondary to a pre-existent ST. Alternatively there may be an underlying vestibular abnormality. The clinical practice of vestibular examination suggests that, if a hyperreactive VOR with or without a significant DP was associated with any other abnormality, it would be motion sickness or vertigo rather than ST. The symptom of dizziness was reported by two of the seven ST patients showing vestibular hyperreactivity in the VS test, and judging from the medical history, these complaints occurred with rather than preceded the ST. A vestibular dysfunction associated with vertigo has been suggested as the cause of recurrent paroxysmal head-tilting or torticollis in infants. The attacks ceased after months or sometimes years and left no residual effect. ${ }^{16}$ It appears that idiopathic ST cannot be simply explained as secondary to a primary cause of vestibular hyperreactivity.

Brain-stem dysfunction, a common cause of both the ST and the vestibular hyperreactivity, is another possibility. Involvement of the brain-stem and possibly the commissure, has been inferred from the observation of ocular counterrolling abnormalities. ${ }^{7}$ Brain-stem involvement at this level has been considered one of the possible causes of vestibular hyperreactivity in multiple sclerosis. ${ }^{10}$

We thank $M G M$ Nicolasen for the vestibular examinations and his computer analysis of the nystagmus responses.

\section{References}

1 Podivinski F. Torticollis (chap 23). In: Vinken PJ, Bruyn GW, eds. Handbook of Clinical Neurology, vol 6. Amsterdam: North Holland, 1968:567-603.

2 Magnus R. Körperstellung. Berlin: Springer Verlag, 1924.

3 Hyndman OR. Torticollis spastica. Suggested etiologic relation of the vestibular apparatus; report of a case. Arch Otolaryngol 1939;29:927-38.

4 Svien HJ, Cody DTR. Treatment of spasmodic torticollis by suppression of labyrinthine activity: report of a case. Mayo Clin Proc 1969;44:825-7.

5 Matthews WB, Beasley P, Parry-Jones W, Garland G. Spasmodic torticollis: a combined clinical study. $J$ Neurol Neurosurg Psychiatry 1978;41:485-92.

6 Bronstein AM, Rudge P. Vestibular involvement in spasmodic torticollis. J Neurol Neurosurg Psychiatry 1986;49:290-5.

7 Diamond SG, Markham CH, Baloh RW. Ocular counterrolling abnormalities in spasmodic torticollis. Arch Neurol 1988;45:164-9.

8 van Hoof JJM, Horstink MWI, Berger HJC, van Spaendonck KPM, Cools AR. Spasmodic torticollis: the problem of pathophysiology and assessment. J Neurol 1987;234:322-7.

9 Huygen PLM. Nystagmometry: the art of measuring 
Vestibular hyperreactivity in patients with idiopathic spasmodic torticollis

nystagmus parameters by digital signal processing. ORL 1979;41:206-20.

10 Huygen PLM. Vestibular hyperreactivity in patients with multiple sclerosis. Adv Oto- Rhino- Laryngol 1983; 30:141-9.

11 Huygen PLM, Nicolasen MGM. The diagnostic value of velocity step responses. ORL 1985;47:249-61.

12 Theunissen EJJM, Huygen PLM, Folgering H Th. Vestibular hyperreactivity and hyperventilation. Clin Otolaryngol 1986;11:161-9.

13 Huygen PLM, Hoogland GA. Vestibular and ocular motor manifestations of cerebellopontine angle tumours. Adv Oto- Rhino- Laryngol 1984;34:57-70.

14 Berthoz A. Adaptive mechanisms in eye-head coordination. In: Berthoz A, Melvill Jones G, eds. Adaptive mechanisms in gaze control. Amsterdam: Elsevier, 1985:177-201.

15 Kubo T, Igarashi M, Jensen DW, Wright WK. Head and eye movements following vestibular stimulation in squirrel monkeys. ORL 1981;43:26-38.

16 Snyder CH. Paroxysmal torticollis in infants. A possible form of labyrinthitis. Am J Dis Child 1969;117:458-60. 